Foods, by Mr. J. Knight, D.Sc. 16. Increa se of the Powtrs of Local Authorities with Regard to Milk-supply, by Dr. A. K. Ohalmers. 17. The Operation of the Midwives Act in Wngland, with a view to its Extension to Scotland and Ireland, in Relation to Infantile Mortality, by Dr. Margaret M. Smith. The papers were followed in turn by a series of resolutions.

Questions and Answers on Nursing for the St. John Ambulanoe Assooiations, and Others. By JoHN W. MaRTIN, M.D.R.U.I. Fifth edition. London: Baillière, Tindall, and Cox. 1906. Pp. 138. Price 1s. 6d. net.-In this, the ffth, edition of this little book a change has been made in the type in which the questions and answers have been printed; by the change the author hopes the reader will be helped in fixing both more easily in his memory. The book has been revised and some additions have been made. The anthor has adhered closely to what is required by the St. John Ambulance Association in the examinations conducted under its auspices. Many of those who are studying nursing will find the book helpful in fixing points of importance and interest upon their memories. It is a useful work, On p. 78, in the answer to the third question, we suppose the word "teacup" is wrongly printed for "teapot."

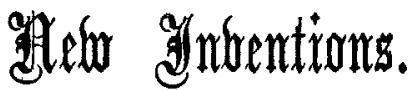

FACIAL PROTECTIVE MASK.

THE frequent liability which those engaged in throat work incur of having the face spat upon and bespattered with visible and invisible expectoration and the toleration with which this has been endured by the faculty would almost persuade one that such can always occur with impurity. It is obrious, however, that the risks of contracting the foulest disorders while examining and treating many pharyngeal and laryngeal affections are great and many. The apparatus that have from time to time been invented

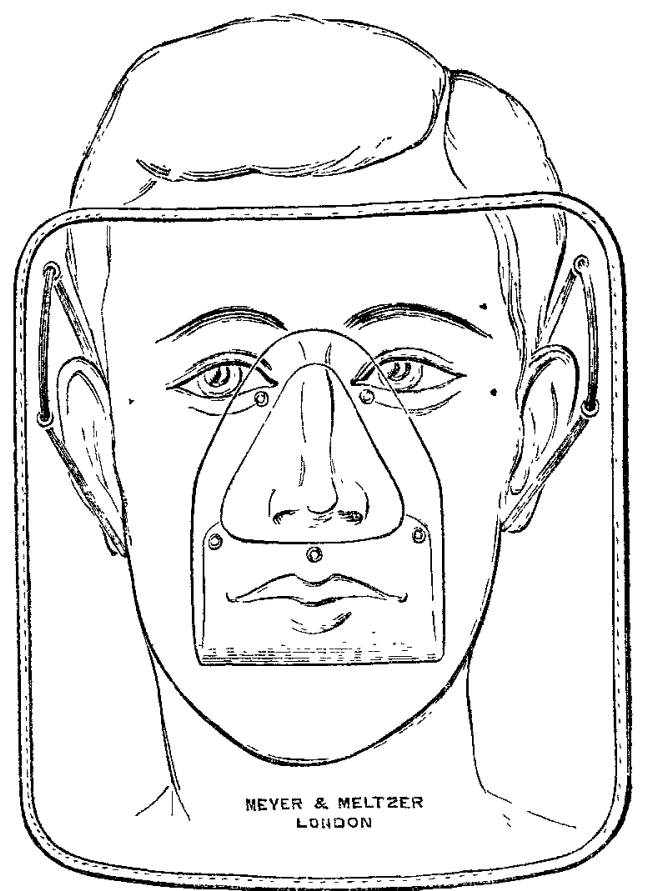

to minimise these dangers have never been universally adopted because of their expensiveness, clamsiness, and awkwardness for ready, quick adjustment. I have found this facial protective mask efficient, and so easy of application that it accomplishes the objects desired. Being composed of mica it is sufficiently light and transparent and can be washed and sterilised by boiling. It is very easy of adjustment, since it is simply looped over the ears by moons of two elastic bands. The mask has the additional merits of durability and cheapness. Messrs. Mayer and Meltzer, 71 , Great Portland-street, are the makers.

$$
\text { W. STUART-Low, F.R.C.S. Eng. }
$$

\section{NEW GASTRO-ENTEROSTOMY CLAMP.}

THE accompanying illustrations show a new pattern gastro-enterostomy clamp which Messrs. Weiss and Son, Limited, of 287, Oxford-street, London, W., have made from my drawings. The clamp is a twin clamp and consists of two forceps ; each forcep consists of a male and female blade. The male blade is straight and fits by an easy mechanical contrivance into the female. Both blades are grooved longitudinally, so that when they are closed they take a firm grip of the mass of tissue between them and do not in any way injure it-in fact, they do not even mark the tissues. The female blade has a double curve, a long one reaching from the tip to the beginning of a short, sharp curve. The length of this long curve is five inches and its outer surface is marked off in a quarter-inch scale, by means of which the length of the incision in the stomach and bowel can be exactly measured, a point of the greatest importance

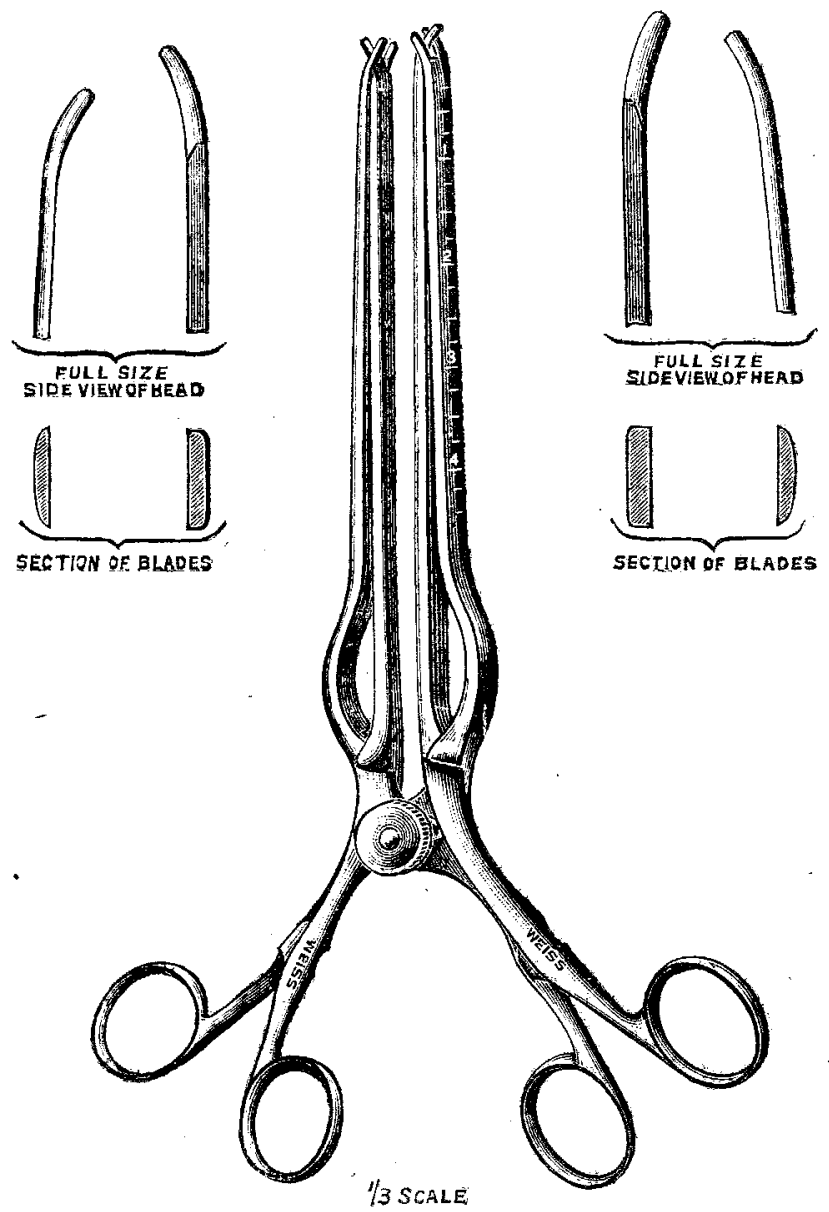

as regards the neatness of the operation. The length of the clamp is about 11 inches. When the blades are closed on the mass of stomach or bowel the female blade presses the tissue against the male blade (there is no compression); it perfectly steadies the tissues and acts also as a hæmostatic forceps. When the forceps are opened for removal there is no tension on the three lines of suture already introduced, and the obtuse angle which the handles make with the blades gives room for both sides of the anastomosis to be examined with the forceps in position, which cannot be done with the twin forceps in which the blades are straight. I claim the following advantages for this clamp over those at present in use. These various points are well shown in the illustrations. (1) It is lighter and can be used without rubber coverings ; (2) it acts as a hæmostatic forceps; (3) the inch scale enables the incisicns to be measured accurately; (4) the bent position of the handles allows all parts of the anas. tomosis to be examined while the clamp is in position; (5) opening each blade of the forceps does not put the sutures on the stretch as some of the present modes do ; and (6) it can be used for any sort of entero-anastomosis as well as gastroenterostomy. I have to thank Messrs. Weiss and Son for the very careful way in which they have carried out my designs and suggestions.

T. Gelston AtKINs, M.D., M.Ch.R.U.I., Surgeon, Cork South Infirmary. 